\title{
醏
}

\author{
Álvaro Espina*
}

\section{UNA PROPUESTA DE REFORMA INTEGRAL DE LA NEGOCIACIÓN COLECTIVA Y LA LEGISLACIÓN LABORAL EN ESPAÑA}

La primera parte del trabajo estudia las últimas reformas del sistema español de negociación colectiva y sus resultados, examinando en forma comparada la estructura regulatoria que ha hecho posible las anomalías presentadas en Espina (2016c). La segunda parte contempla de forma integrada el marco institucional, que arranca con el derecho constitucional a la negociación colectiva, incluye los preceptos de los convenios de la OIT aplicables a la misma, continúa con la Ley Orgánica de libertad sindical, el Estatuto de los Trabajadores y el resto de la normativa laboral, para materializarse y encontrar reforzamiento mutuo en prácticas colectivas recurrentes profundamente arraigadas, que canalizan además efectos de contagio internacional desde los países con niveles de productividad y salarios más elevados y estructuras de organización empresarial distintas a las de nuestro país. Lo que viene a revelar el análisis contenido en esta parte del trabajo es que, en el caso español, esta estructura institucional constituye una especie de bucle casi cerrado con características que, en buena medida, resultan únicas dentro de la Unión Europea y deben modificarse.

En la tercera parte del trabajo se esbozan las líneas fundamentales de una reforma del sistema español de negociación colectiva que se enmarca en un proyecto de reforma integral de nuestra legislación laboral.

Palabras clave: convenios colectivos, legislación laboral, Estatuto de los Trabajadores, OIT.

Clasificación JEL: J31, J52.

\section{Introducción: la negociación colectiva debe descentralizarse}

Hace tiempo que los analistas del mercado de trabajo vienen reclamando una reforma de la negociación colectiva que permita llevar a cabo la más completa descentralización (BentolilaJimeno, 2002), desmontar los mecanismos que

* Consejero técnico. Dirección General de Política Económica. Versión de agosto de 2016. colocan en posición de inferioridad absoluta a los trabajadores menos cualificados y a las pequeñas empresas (Dolado, et al., 1997), así como a las regiones menos desarrolladas (Jimeno y Bentolila, 1998), dando amplia prioridad a los convenios de empresa sobre los de cualquier otro ámbito ${ }^{1}$. Antes de las últimas reformas, Bentolila, Izquierdo y Jimeno (2010) $\triangleright$

1 Sobre las migraciones regionales desde 2008, véase Minondo et al. (2013) y sobre las diferencias de paro entre regiones, Fernández et al. (2010). 
consideraban imprescindible alterar la legitimación para negociar convenios de ámbito superior a la empresa; permitir mayor concurrencia de convenios colectivos de distinto ámbito y la adaptación de la aplicación de los convenios colectivos sectoriales a las necesidades coyunturales de las empresas, y limitar la ultraactividad de los convenios.

Un buen inventario de toda esta literatura se contiene en «Nueve propuestas para la reforma de la negociación colectiva en España» firmada por catorce economistas de Fedea en marzo de $2011^{2}$, agrupadas en cinco grandes objetivos: 1) Descentralización, admitiendo la concurrencia entre convenios de empresa y de otro ámbito. 2) Limitación de la eficacia general de los convenios colectivos (sometida a amplia representatividad efectiva de las comisiones negociadoras respecto al empleo y las empresas del ámbito territorial específico en que se aplican). 3) Limitación de la ultraactividad de las cláusulas normativas de los convenios a un año tras la expiración del plazo inicial. 4) Mejora de la coordinación para recuperar la competitividad y el empleo. 5) Desindexación, evitando cláusulas automáticas de revisión asimétrica de los salarios.

La OCDE sintetiza la aplicación de su estrategia de empleo en esta materia afirmando:

«Descentralizar la negociación colectiva, facilitando la posibilidad de que los empleadores se autoexcluyan de los convenios supraempresariales en tiempo de crisis, neutralizaría la destrucción de empleo a corto plazo inducida por la regulación del mercado de productos y las reformas protectoras del empleo.... La negociación a escala sectorial o regional induce frecuentemente contagio entre sectores, elevando los salarios en tiempo de expansión y retrasando el necesario ajuste en tiempos de crisis. En cambio, la flexibilidad relativa derivada

\footnotetext{
2 http://www.fedea.net/negociacion-colectiva/PDF/9-propuestasnegociacion-colectiva.pdf
}

de la negociación a escala de empresa permite un mejor ajuste del crecimiento de los salarios al crecimiento de la productividad de la empresa, contribuyendo a salvar empleos en los malos tiempos al permitir a las empresas utilizar márgenes distintos del empleo (salarios, tiempo o condiciones de trabajo)... mientras que España se ha caracterizado por confiar casi exclusivamente la absorción de los choques al ajuste del empleo» (OECD, 2016, p. 148).

Tras el análisis de la reforma laboral española de 2012 (OCDE, 2014), al compararla ahora con las realizadas en varios países, su evaluación establece que «en países con regímenes de negociación colectiva supraempresarial combinar las reformas de la legislación protectora del empleo con la flexibilización de la negociación colectiva contribuye a neutralizar las pérdidas de empleo a corto plazo durante el período de ajuste».

Por su parte, en su reciente evaluación de las políticas de la eurozona el FMI enuncia el siguiente inventario de las reformas todavía pendientes en España: «Alinear el crecimiento de los salarios con la productividad y la competitividad externas, permitiendo la diferenciación entre empresas y sectores; llevar a cabo la negociación salarial a escala de la empresa y disponer de cláusulas de autoexclusión (opt-out), especialmente para las pequeñas empresas; aproximar los costes de despido entre contratos temporales y permanentes; reducir las incertidumbres legales y administrativas en los despidos colectivos, y establecer criterios objetivos para los despidos procedentes" (IMF, 2016/40; cursiva: $A E)$.

\section{Vicisitudes de la reforma de 2012}

En 2011 y 2012 dos Gobiernos sucesivos de distinta orientación política realizaron reformas legislativas que, en lo que se refiere a la $\triangleright$ 
negociación colectiva, Bentolila, Dolado y Jimeno (2012) resumieron de este modo:

«La reforma de 2011 otorgó prioridad a los convenios colectivos de empresa respecto a los de industria, a no ser que hayan sido expresamente prohibidos por estos últimos. Se permitió a las firmas que atraviesan dificultades a descolgarse de los niveles salariales del convenio colectivo de la rama por acuerdo con sus trabajadores, si bien el nivel correspondiente ha de ser recuperado en un plazo máximo de tres años. Transcurrido un año de expirar la vigencia de un convenio sin haberse alcanzado nuevo acuerdo deberá ser sometido a arbitraje. En suma, la reforma mantuvo los principios que favorecen la negociación a nivel de rama, levantando marginalmente algunas restricciones para las cláusulas de no aplicación (opt-out).

La reforma de febrero de 2012 suprimió la posibilidad de que los convenios de ámbito superior prohibieran disponer o no aplicar sus cláusulas por los convenios de empresa. Se permitió a los empresarios modificar unilateralmente las condiciones de trabajo, incluidos los salarios, cuando estos superan el nivel del convenio colectivo de rama (en cuyo caso el trabajador puede optar por abandonar su empleo, percibiendo la indemnización de despido por circunstancias económicas, o demandar a la empresa ante la jurisdicción). Las causas de dificultad que puede alegar la empresa para no aplicar el convenio se especifican más, consistiendo en haberse registrado pérdidas (anualizadas) durante dos trimestres sucesivos. La duración máxima de las condiciones establecidas por los convenios no renovados será de dos años ${ }^{3}$ tras expirar su vigencia y deberán someterse a arbitraje obligatorio; los convenios de ámbito superior no pueden prohibir el límite de vigencia ni el arbitraje. Se

3 En su conversión en Ley 3/2012 este plazo quedó reducido a un año desde la denuncia del anterior. suprime la autorización administrativa de los acuerdos colectivos de suspensión de contratos o reducción del tiempo de trabajo».

A su juicio, las reformas iban a producir un desplazamiento sustancial del poder de negociación desde los trabajadores a los empleadores (aunque referido especialmente a la disminución de las indemnizaciones por despido, incluida también en la reforma), aunque se echaban en falta genéricamente medidas para mejorar la productividad. Dolado (2012) hizo una simulación de la probabilidad de que una pequeña empresa flexibilizara sus salarios haciendo uso de las cláusulas de no aplicación de los convenios de ámbito superior, observando que los costes administrativos de tal proceder serían demasiado elevados, ya que, salvo que se haga por acuerdo con los trabajadores, según el artículo 82.3 del Estatuto de los Trabajadores (ET) la empresa se vería obligada a obtener la autorización sucesiva de cuatro instituciones legales antes de salir del convenio (la Comisión Paritaria, la del Convenio de Rama, la Comisión Consultiva y el Arbitraje), lo que resulta generalmente disuasorio y difícilmente practicable para la empresa, especialmente cuando se encuentra al borde del concurso. Además, la parte laboral también puede apelar ante las comisiones consultivas, nacional o de comunidad autónoma.

Cruz Villalón (2015a) señaló que, con algunas salvedades, la reforma dejó incólumes los pilares básicos del modelo de negociación colectiva vigente desde la transición:

«Podría afirmarse que el cuadro normativo general sustentador del modelo pervive. En efecto, permanecen las reglas básicas relativas a los sujetos legitimados -que permiten un intenso protagonismo sindical del proceso-; a la eficacia general del convenio colectivo -que propicia una amplia tasa de cobertura-; a la libertad de fijación de ámbitos -que da pie a la pervivencia de una amplia red de convenios sectoriales-, así como a la amplitud de contenidos $\square$ 
negociales, que procura que los convenios colectivos asuman un papel central en la determinación de los [mismos]...».

Sin embargo, aun calificando la reforma como "cambio fundamental en las posiciones de equilibrio de las partes», su propio examen de la evidencia empírica disponible tras tres años de aplicación (siendo una de las más detalladas) arroja un balance de impacto extraordinariamente moderado y poco estimulante para las microempresas:

«...el porcentaje de trabajadores afectados por convenios de empresa sobre el total ha ido disminuyendo..., pasando del 10,15 por 100 en 2008..., al 6,56 por 100 en 2013.... El descenso en el número medio de trabajadores de las plantillas de las empresas cubiertas por convenios sectoriales entre el año 2012 y 2013, donde se pasa de 7,88 trabajadores a $6,73 \ldots$, puede significar que las empresas pequeñas están pasando a negociar sus propios convenios, quedando el nivel sectorial para las muy pequeñas o micro empresas, donde no se alcanzan las plantillas mínimas para tener órganos de representación estatutaria o unitaria» $(2015 b / 43-44)^{4}$.

Malo (2012) consideró que la verdadera vía de descuelgue para la empresa consistiría en negociar un convenio propio, al que la reforma otorgaba prioridad sobre el de ámbito superior en los asuntos más sustanciales (salarios, complementos, primas, distribución de la jornada de trabajo, etc.), sin necesidad de esperar a la expiración del convenio de rama (aunque este siga vigente como marco general), pero otorgaba todavía mayor relevancia para la renovación de la negociación colectiva al límite de un año fijado para la ultraactividad.

\footnotetext{
${ }^{4}$ Los trabajadores con convenio de empresa pasaron de 926.000 en 1912 a 764.000 en 2015. Los con convenio de ámbito superior, de 9.173.000 a 7.850.000. Los máximos se habían alcanzado en 2008-2009 con 1.262.000 y 10.753.000, respectivamente. En 2013 las inaplicaciones afectaron a 160.000 trabajadores, 2/3 de los cuales relacionados con remuneración y salarios (Cruz Villalón (2015b/182).
}

No minusvaloraba, sin embargo, el riesgo de bloqueo e incertidumbre derivada de la interpretación jurisprudencial.

El primero de estos últimos se materializó parcialmente por la sentencia de casación 264/2014 del Tribunal Supremo de 22/12/2014 que rechazó el recurso de casación presentado por la empresa ATESE frente a la sentencia del TSJ de las Illes Balears en el conflicto colectivo que se declaró tras expirar la vigencia de la ultraactividad del convenio colectivo anteriormente vigente sin haber suscrito uno nuevo y sin existir un convenio de ámbito superior aplicable. La sentencia recurrida declaraba no ajustada a derecho la conducta de la empresa, obligándola a reponer «... a los trabajadores afectados por el conflicto colectivo a las condiciones que disfrutaban con anterioridad, durante la vigencia del expresado convenio colectivo." Para rechazar el recurso el Tribunal Supremo (TS) se apoyó en la doctrina "conservacionista», según la cual:

«Los derechos y obligaciones de los trabajadores son aquellos por los que se rigió su contratación, plasmados en el contrato de trabajo bien de forma expresa, bien por remisión al convenio colectivo de aplicación».

En su razonamiento el TS admite de plano esta doctrina (traída del Código Civil), aunque limitándola a la regulación de los contratos de trabajo firmados durante la vigencia del convenio, no a los nuevos, ya que aquellas condiciones contractuales... «carentes ya del sostén normativo del mínimo convencional, podrán ser modificadas, en su caso, por la vía del art. $41 \mathrm{ET}$.... Y, por la misma razón, los trabajadores de nuevo ingreso carecerán de esa malla de protección que brindaba el convenio fenecido".

De este modo, el alcance que buscaba el legislador de la reforma en materia de ultraactividad se ha visto muy limitado, profundizando aún más la divisoria insiders/outsiders de que viene adoleciendo el mercado de trabajo español, $\square$ 
causa del estancamiento de la productividad total de los factores productivos (Dolado et al. 2010).

Sin embargo, otras dos incertidumbres ya fueron despejadas por la OIT y el Tribunal Constitucional, que consideró acorde con la Constitución el arbitraje obligatorio público de la inaplicación empresarial de los convenios de ámbito superior (los descuelgues) ${ }^{5}$, así como la preferencia aplicativa de los convenios o acuerdos de empresa. Sobre esta última establece que tal preferencia no entra en colisión con el reconocimiento constitucional del derecho a la negociación colectiva ni vulnera la consideración de la actividad sindical como contenido constitucional de la libertad sindical ${ }^{6}$ (Cruz Villalón 2015a). De esta forma adquieren legitimación constitucional algunos de los denominados «convenios extraestatutarios" - de eficacia limitada a los suje tos legítimamente representados de forma directa en la negociación colectiva-, en la línea defendida hasta ahora por una parte de la doctrina, en contra de la interpretación habitual ${ }^{7}$.

Pero el que no incurra en infracción de precepto constitucional alguno no implica que con la reforma hayan quedado despejadas todas las incertidumbres jurisdiccionales que pesan sobre la prioridad de los convenios colectivos de empresa, puesto que en otras instancias podría ser considerada contraria al modelo legal de negociación colectiva, regulado por el conjunto de normas que desarrollan aquellos

\footnotetext{
5 El CLS-OIT cerró el caso en junio 2016. El TC en las sentencias 119/2014 (16-07) y 8/2015 (de 22-01): http://www.ilo.org/dyn/normlex/es/f?p=1000:50002:0::NO:50002:P50002_COMPLAINT_TEXT_I $D: 3282089$

6 La sentencia 8/2015 confirma la constitucionalidad de los artículos $41,51,84.2$ y disposición adicional $10^{\mathrm{a}}$ del ET en la redacción contenida en la Ley $3 / 2012$. Previamente el TS $(26 / 03 / 14)$ y la AN (10-09-2012) habían declarado la nulidad de las cláusulas que no reconozcan la prioridad de los convenios de empresa en las materias concretas enumeradas en la reforma (no en materia de duración de contratos) (Cruz Villalón (2015a/14 y ss.). Estas pueden negociarse pero solo entran en vigor al expirar el convenio.

Véanse, por ejemplo, Goerlich Peset (2008 y 2014, pp. 271-272). Cruz Villalón (2015a) niega esta capacidad a los acuerdos de empresa negociados por comisiones ad hoc.
}

preceptos constitucionales, incluidas las leyes orgánicas y los convenios internacionales ratificados por España que se sitúan inmediatamente por debajo de ella.

El dualismo en la interpretación del grado de descentralización regulatoria conseguido efectivamente por la reforma de 2012 se observa en las ponencias de Cruz Villalón y Del Rey Guanter a las XXVII jornadas de Estudio de la CCNCC (2015). Para el primero, si los agentes negociadores lo desean el «dirigismo legal» no puede arrebatarles la facultad de autorregulación al nivel que ellos mismos planteen (pp. 35-7), mientras que para el segundo, la empresa es libre de tener convenio propio con plena capacidad normativa o acogerse al sectorial (p. 70). Este enfrentamiento doctrinal implica incertidumbre y riesgo. Evaluarlo, así como fijar los límites de la normativa legal que regula el funcionamiento y el alcance de la negociación colectiva, requiere examinar cuidadosamente todo el entramado normativo en términos comparativos.

\section{El sistema español de negociación colectiva y sus bloques constitutivos en perspectiva comparada}

La Tabla 1 sistematiza en catorce columnas el marco institucional y las principales características de los sistemas de negociación colectiva (en adelante NC) de ocho países de la Unión Europea (seis de la eurozona). El criterio de selección es el utilizado por los servicios jurídicos del Senado francés al comparar la capacidad normativa de los poderes legislativos para regular la negociación colectiva y la representación sindical, considerando a este grupo de países como el más relevante a tales efectos. Dadas las similitudes de nuestro modelo, la selección es igualmente significativa en nuestro caso. 


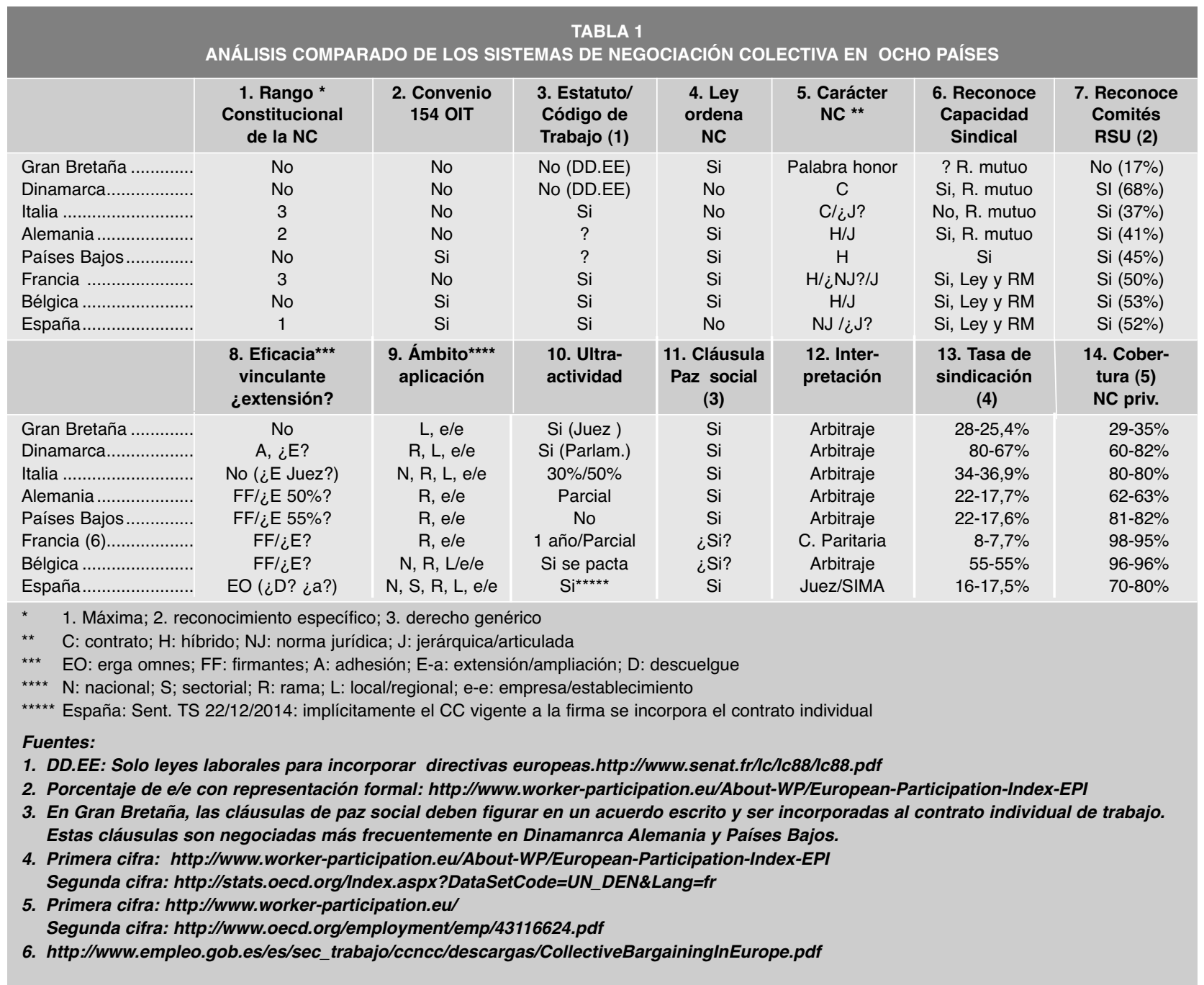

En síntesis, aquel estudio detectaba una enorme diversidad de marcos institucionales. En lo que se refiere a la protección normativa de la acción colectiva, Dinamarca y España se sitúan en los polos opuestos: en Dinamarca son los interlocutores quienes organizan el mercado de trabajo libres de toda intervención del Estado y de toda regulación producida a través de la ley. En cambio, en España la NC se encuentra garantizada por la Constitución, los convenios colectivos tienen carácter normativo cuasilegal, disfrutan de la amplísima autonomía regulatoria que aparenta conferir el Convenio 154 de la OIT y se encuentran tipificados como norma jurídica en el artículo 3 del Estatuto de los Trabajadores, que los diferencia claramente de la voluntad de las partes manifestada en el contrato (frente al caso de Italia, en que se consideran "contratos normativos»). Todo ello viene a ser, en la práctica, una deslegalización realizada en favor de la normativa autónoma producida por las organizaciones sindicales y empresariales mediante la NC.

En otro orden de cosas Francia es, de todos los casos estudiados, aquel en que la ley y la autoridad administrativa (personal, del ministro de Trabajo, o colectiva, como la que en España ostenta la CNNC) dispone de mayores facultades para enmarcar e intervenir en la negociación, y también en este aspecto España es la que dispone de menor capacidad $D$ 
de intervención ${ }^{8}$ (aunque esta no sea tan minimalista como pretenden los defensores a ultranza del modelo «autonomista»). ¿A qué se debe y cómo se encuentra articulada la posición ultrancista española en materia de negociación colectiva, causante de las distorsiones examinadas en Espina (2016c)?

La columna 1 indica que de los siete países España es también aquél en que la NC dispone de una protección constitucional más vigorosa ya que Dinamarca, Bélgica y Países Bajos no la incluyen en su Constitución, Gran Bretaña no la tiene, Francia ${ }^{9}$ e Italia la enuncian como un derecho genérico y Alemania como un derecho específico $^{10}$. Los enunciados de la CE referidos a la NC y a los derechos y garantías anejos son los siguientes (en cursivas figuran los límites legales, nacionales y trasnacionales y los mandatos de intervención para su ejercicio).

Título Preliminar, artículo 7: «Los sindicatos de trabajadores y las asociaciones empresariales contribuyen a la defensa y promoción de los intereses económicos y sociales que les son propios. Su creación y el ejercicio de su actividad son libres dentro del respeto a la Constitución y a la ley. Su estructura interna y funcionamiento deberán ser democráticos".

Título I, artículo 10.2: «Las normas relativas a los derechos fundamentales y a las libertades

\footnotetext{
${ }^{8}$ Debido, según Federico Durán, a «la antigualla corporativa del carácter normativo del convenio colectivo», y a la anomalía española de no establecer claramente su naturaleza contractual: $h t t p: / / c i n$ codias.com/cincodias/2008/03/10/economia/1205265348_850215.html. También En el mismo sentido véase: $h$ ttp://nadaesgratis.es/marceljansen/la-contractualizacion-del-convenio-colectivo

9 Su preámbulo dice: «Todo trabajador asalariado participa, a través de sus delegados, en la determinación colectiva de las condiciones de trabajo", aunque no llega a garantizar el principio de libertad contractual. Además el artículo 34 atribuye al legislador el poder de «determinar los principios fundamentales del derecho del trabajo, del derecho sindical y de la seguridad social».

10 El artículo 39 de la Constitución italiana facultó a los «sindicatos registrados», en proporción a su número de afiliados, a «firmar convenios colectivos de trabajo con capacidad de obligar a todos los miembros y categorías profesionales de su ámbito de aplicación». Como no es directamente aplicable y no se ha desarrollado, todo el mundo de las RRII se rige por el derecho civil (Veneziani en CCNCC 2004/158). En PPBB la litigiosidad se dirime también ante la jurisdicción civil, aunque el ministro puede declarar nulo un convenio y el Gobierno suspenderlo durante un año (Asser, en CCNCC 2004/150153). En Alemania, los negociadores deben contar siempre con mandato directo: Stephen-Schroeder (2007).
}

que la Constitución reconoce se interpretarán de conformidad con la Declaración Universal de Derechos Humanos y los tratados y acuerdos internacionales sobre las mismas materias ratificados por España».

Título I, capítulo 2: artículos relacionados con la acción colectiva:

Artículo 28.1: «Todos tienen derecho a sindicarse libremente. ....La libertad sindical comprende el derecho a fundar sindicatos y a afiliarse al de su elección, así como el derecho de los sindicatos a formar confederaciones y a fundar organizaciones sindicales internacionales o a afiliarse a las mismas. Nadie podrá ser obligado a afiliarse a un sindicato".

Artículo 35: «Todos los españoles tienen el deber de trabajar y el derecho al trabajo, a la libre elección de profesión u oficio, a la promoción a través del trabajo y a una remuneración suficiente para satisfacer sus necesidades y las de su familia, sin que en ningún caso pueda hacerse discriminación por razón de sexo". Nㅜㄴ 2 : «La ley regulará un estatuto de los trabajadores».

Artículo 37.1: «La ley garantizará el derecho a la negociación colectiva laboral entre los representantes de los trabajadores y empresarios, así como la fuerza vinculante de los convenios».

Artículo 37.2 reconoce: «El derecho de los trabajadores y empresarios a adoptar medidas de conflicto colectivo. La ley que regule el ejercicio de este derecho, sin perjuicio de las limitaciones que puedan establecer, incluirá las garantías precisas para asegurar el funcionamiento de los servicios esenciales de la comunidad».

Artículo 38: «Reconoce la libertad de empresa en el marco de la economía de mercado. Los poderes públicos garantizan y protegen su ejercicio y la defensa de la productividad, de acuerdo con las exigencias de la economía general y, en su caso, de la planificación.

Título I, capítulo 3, artículo 40.1: «Los poderes públicos promoverán las condiciones $\triangle$ 
favorables para el progreso social y económico y para una distribución de la renta regional y personal más equitativa, en el marco de una política de estabilidad económica. De manera especial realizarán una política orientada al pleno empleo».

El primer aspecto diferencial en esta materia proviene de la ratificación o no ratificación del Convenio 154 de la OIT ${ }^{11}$, que obliga a los Estados firmantes a fomentar que los agentes colectivos dispongan de amplias facultades para ordenar con autonomía la estructura y el alcance de los convenios colectivos, lo que ha venido interpretándose en forma muy laxa como la delegación automática de las atribuciones del legislador ordinario en estas materias. De mantenerse tal interpretación, la ratificación del Convenio habría significado la renuncia a unas facultades que resultan imprescindibles para ordenar todo este marco normativo, haciendo primar la autorregulación sobre la heterorregulación y renunciando con ello de facto el legislador nacional a dictar normas que faciliten la mejor adecuación de este marco normativo al proceso de globalización y a los objetivos de la política macroeconómica. Todos los aspectos básicos del modelo español de NC enunciados por Cruz Villalón (2015a), ya examinados, vienen imputándose a la aplicación de ese Convenio, que en su interpretación maximalista resultaría de aplicación directa por los tribunales ${ }^{12}$, aunque esto sea abiertamente cuestionable.

Pues bien, de entre los siete países, solo tres han ratificado este convenio: España, Bélgica y Países Bajos (Tabla 1, columna 2), aunque en

\footnotetext{
11 «Sobre la negociación colectiva», 1981, C. n 154, 11-VIII-1983. Ratificado por España el 11/09/ 1985.

http://www.ilo.org/dyn/normlex/es/f?p=NORMLEXPUB:12100:0: NO:12100:P12100_INSTRUMENT_ID:312299:NO. En adelante: C. 154.

12 Véase Falguera (2012). La estadística de menciones de Convenios OIT en los pronunciamientos del Tribunal Supremo entre 1978 y 2011 computa máximos de hasta 50 citas en 1989 y hasta 20 en 2007. También para Goerlich (2014) la arquitectura doctrinal de nuestro modelo es el Convenio 154. No así para Federico Durán: http://cincodias.com/cincodias/2015/02/02/economia/ 1 422899601_685954.html.
}

Países Bajos los CC no tienen eficacia erga omnes salvo caso de extensión (que excluye siempre a las empresas con convenio propio: Asscher-Vonk, en CCNCC 2004, p. 142). Bélgica y Países Bajos, en donde la NC no disfruta de protección constitucional, disponen de estructuras empresariales y territoriales enormemente homogéneas (como sucede también en Suecia $^{13}$ y Finlandia, países igualmente ratificadores del C. 154), por lo que los efectos de contagio pueden llegar a resultar eficientes (como lo eran en la antigua RFA: Espina, 2016b). En cambio no lo han ratificado los otros cinco países de nuestra selección (Francia, Alemania, Dinamarca, Italia y Gran Bretaña), como tampoco Austria, Bulgaria, la República Checa, Estonia, Irlanda, Luxemburgo, Malta, Polonia y Portugal.

El examen detenido de la columna $3^{14}$, arroja el balance de que, con mucho, la normativa más detallada en materia de regulación legal es la española. El Estatuto de los Trabajadores (ET) regula una amplísima gama de ámbitos de la relación laboral como derecho necesario, aunque deja las materias más sustanciales a la delimitación, la estructuración y la libre negociación entre las partes sin intervención del Estado. De acuerdo con las columnas 4 y 5 España es el único caso en que la Ley no desarrolla sus facultades de ordenación de la $\mathrm{NC}$, al mismo tiempo que se otorga al CC la consideración de fuente jurídica de elevada jerarquía normativa y se concede a los interlocutores de la negociación amplias facultades regulatorias, en línea con la interpretación maximalista del C. 154, aunque la Sentencia del TC 58/1985 señaló que la ley puede «desplegar una virtualidad limitadora» de la NC y $\triangleright$

\footnotetext{
${ }_{13}$ Pese a ello, en Suecia no existe el concepto de eficacia erga omnes Norberg et al. (en CCNCC 2004), p. 240. Además, el despido por reestructuraciones para mejorar la rentabilidad se considera justo (p. 260).

${ }_{14}$ Analizado, junto al resto de la tabla, en la tercera parte del Cuaderno de Documentación $n^{\circ}$ 107-Final: http://imagenesbibliote cacentral.minhap.gob.es/pdfpublicaciones//Literaturagris/cd107_fina I_2016.pdf
} 
reservarse para sí determinadas materias quedando estas excluidas de la contratación colectiva.

El título tercero del ET español regula los convenios colectivos y la legitimidad contractual. En los convenios supraempresariales siempre están legitimados los sindicatos más representativos a nivel nacional, de CCAA o de otro ámbito y las organizaciones afiliadas y federadas a las primeras. Las de empresarios deben contar al menos con un 10 por 100 de las empresas y empleados afectados (o solo con un 15 por 100 de los empleados afectados). En cualquier caso lo más frecuente es que la representatividad no se cuestione y derive de que ambas partes se reconozcan como interlocutores.

Las columnas 8,9 y 10 recogen los efectos, el alcance y la eficacia de los convenios y acuerdos colectivos. En la primera sobresale el hecho de que España sea el único país analizado en que los CC «estatutarios» disponen sin más trámites de eficacia general (erga omnes). Según los analistas del Senado francés «en España los procedimientos de extensión stricto sensu son inútiles, ya que, en los términos de la ley, los CC firmados por las organizaciones representativas resultan vinculantes para todos los asalariados y empleadores a quienes se dirige, cualquiera que sea la pertenencia sindical de unos y otros» ${ }^{15}$. En general, en el contexto europeo la extensión de un convenio colectivo significa darle eficacia general, algo que en España tiene ya todo convenio colectivo estatutario. Lo que el artículo 92 del ET español denomina «extensión» no es tal en la denominación de los otros países, puesto que de lo que se trata es de ampliar el ámbito de aplicación inicial, por lo que tal procedimiento se denomina «ampliación».

15 Ya que, de acuerdo con el artículo 82.3 del ET «...obligan a todos los empresarios y trabajadores incluidos dentro de su ámbito de aplicación y durante todo el tiempo de su vigencia».
El carácter automático de la extensión que contiene el artículo 82.3 del ET proviene de una interpretación ultrancista del artículo 37.1 de la $\mathrm{CE}$, que encomienda textualmente a la ley «garantizar la fuerza vinculante de los convenios", como si ese mandato hubiera constitucionalizado el carácter erga omnes de todos ellos, vaciando a la ley de contenido regulatorio específico, superponiéndose a la interpretación también maximalista del Convenio 154 de la OIT. Aunque esta interpretación sea abiertamente cuestionable, la doctrina mayoritaria la considera como el «modelo español de negociación colectiva».

La columna 8 indica que en Europa el ámbito de aplicación de los convenios colectivos suele circunscribirse stricto sensu a sus firmantes, aunque en varios países quepa extenderlo (no en Gran Bretaña, desde 1980: Neal, en CCNCC 2004/206). En algunos casos la extensión puede producirse por adhesión voluntaria (opt-in) ${ }^{16}$. Esto sucede en Dinamarca, en donde no existe procedimiento específico, y en Italia (pero en este caso solo cuando los tribunales aplican directamente el precepto constitucional de igualdad).

En los demás casos la extensión para dotar de eficacia general a un $\mathrm{CC}$ requiere acudir a un procedimiento formal, que en Italia está reservado a los jueces (siempre que el contrato lo mencione). En Bélgica, Países Bajos y Alemania el procedimiento está regulado legalmente, fijándose como condición en estos dos últimos casos que el CC ya esté vigente de forma directa para el 50 y el 55 por 100 (respectivamente) de los trabajadores que vayan a verse afectados. En Francia y Países Bajos la decisión corresponde al ministro del ramo. En Alemania -cuyos $\triangleright$

\footnotetext{
${ }^{16}$ Algo que también prevé en España el artículo 92.1 del ET, otorgando a las partes legitimadas para negociar un convenio la facultad de adherirse íntegramente a la totalidad de uno, lo que en realidad despoja a los negociadores a escala de empresa de su derecho constitucional a la negociación (Goerlich, 2014, p. 271), aplicable también al artículo 3.1.b del ET, que parece otorgar al convenio colectivo una eficacia normativa independiente de las partes firmantes.
} 
convenios tienen también carácter contractual y eficacia limitada por ley a las organizaciones firmantes y a sus miembros, aunque la jurisprudencia impide al empresario discriminar salarialmente entre trabajadores (Zachert, en CCNCC 2004/45) - la extensión precisa informe favorable de la comisión paritaria (como en España la ampliación) aunque desde 2000 son algo excepcional y en 2012 ya resultaban prácticamente inexistentes (Eurofound, 2015/17), mientras que en Bélgica es precisamente el ámbito de aplicación de las comisiones paritarias constituidas por la NC el que delimita el perímetro de la extensión, que debe realizarse por decreto, respetando el ámbito, federal/regional (Engels, en CCNCC 2004/54,70,75).

Con la excepción de Gran Bretaña, en que dominan absolutamente los acuerdos de empresa individual, la columna 9 indica que predomina la negociación y los CC supraempresariales. Vale decir que en el caso de España la doctrina se ha inclinado tradicionalmente por dar prelación a los CC sectoriales (Cruz Villalón, 2015a) y la realidad ofrece concretamente un abierto predominio de los $\mathrm{CC}$ sectoriales provinciales (Bande et al., 2010). En términos comparados (Simón, 2010) ${ }^{17}$ el modelo prevaleciente en España deriva del contagio de los CC de sector-región del modelo alemán, por contraposición al caso de Francia, en que adquieren amplio protagonismo los acuerdos de empresa y de establecimiento (lo que explica la elevada productividad del trabajo y la eficiencia en el uso del capital de ese país, documentada por los datos de AMECO), ya que «la respuesta de los salarios a la heterogeneidad empresarial y a sus cambios resulta crucial para la asignación eficiente de los recursos y los incentivos para innovar e introducir nueva

\footnotetext{
17 Tabla 1. En este trabajo se establece también que España es el país estudiado en que mayor influencia tiene el salario de convenio para fijar la remuneración de los nuevos contratados (tabla 2), así como el elevado grado de homogeneidad y compresión que muestran los salarios españoles a lo largo del tiempo, frente a la creciente dispersión y flexibilidad en los países de la eurozona.
}

tecnología..., poniendo freno a la destrucción creativa de los mercados más dinámicos", moderando la desaparición de empresas y empleo especialmente en tiempos de crisis y aceleración del cambio (Barth et al., 2016).

Ya se dijo que la ambición de la última reforma española de pretender truncar drásticamente la ultraactividad ha quedado muy mermada por la sentencia del TS de 22-XII-2014, que puede considerarse doctrina firme y definitiva en tanto no se acometa una reforma integral de toda la arquitectura de nuestra NC (Conde et. al, 2010). La columna 10 deja claro que España es también en materia de ultraactividad un caso anómalo.

La columna 11 indica que, frente al arbitraje ordinario admitido en el resto de los países -protagonizado por las comisiones paritarias en el caso de Francia- la anomalía española exige arbitraje judicial en caso de no llegarse a un acuerdo ante el servicio interconfederal de mediación y arbitraje (SIMA). Finalmente, la combinación de las tasas de afiliación sindical y las tasas de cobertura de las columnas 13 y 14, convertidas en categorías alta/media/baja permite construir la Tabla 2, en la que destaca la posición extrema de Francia y España.

\begin{tabular}{|c|c|c|c|}
\hline \multicolumn{4}{|c|}{ TABLA 2} \\
\multicolumn{3}{|c|}{ TASAS DE AFILIACIÓN Y COBERTURA } \\
\hline Cobertura & \multicolumn{3}{|c|}{ Afiliación } \\
\hline Neg col. & Alta & Media & Baja \\
\hline Alta............. & Dinamarca/Bélgica & Italia/PPBB & Francia/España \\
\hline Media ......... & XXX & Alemania & XXX \\
Baja........... & XXX & Gran Bretaña & XXX \\
\hline Fuente: elaboración propia. & & \\
\hline
\end{tabular}

En ambos casos con las menores tasas de afiliación se alcanzan elevadas tasas de cobertura de la negociación colectiva en el sector privado, desequilibrio que produce una dinámica de retroactuación, ya que al otorgar a los sindicatos y organizaciones patronales una representatividad independiente de su nivel de afiliación se estimula la actitud free-rider y se desincentiva la pertenencia a unos y otras, $D$ 
con la consiguiente disminución en el grado de control efectivo al que se ve sometida la actuación de sus dirigentes por parte de los afiliados, lo que contrasta igualmente con las estructuras de afiliación y representación vigentes en la $\mathrm{UE}^{18}$, que facilitan modalidades de organización del mercado de trabajo favorecedores de la innovación empresarial, por contraposición a los sistemas de descentralización intermedia que son los más indeseables a estos efectos (Haucap-Wey, 2004/16).

Los últimos estudios realizados por la Comisión Europea indican que la práctica de la extensión de convenios ha decaído persistentemente a lo largo de la crisis en toda la Unión, al mismo tiempo que se reforzaba la tendencia hacia la descentralización y el predominio de la negociación de empresa. El caso extremo fue el de Rumanía, en donde una ley de 2011 prohibió la negociación supraempresarial, pero en general allí donde sigue practicándose los acuerdos alcanzados en los ámbitos superiores no dejan de abrir espacios para que la fijación concreta de los salarios y las condiciones de trabajo se lleve a cabo en la empresa, limitándose a adoptar cláusulas abiertas, simplemente orientativas. En Francia esto viene regulado por la ley. Además, es cada vez más frecuente la derogación del principio de prevalencia de la cláusula más favorable, en los casos en que se produce concurrencia entre lo que establece el convenio de ámbito superior y el de empresa (Ibíd., pág. 215).

En realidad, basta con la Tabla 2 para sintetizar la excepcionalidad española. Podría pensarse que no lo es tanto porque Francia se encuentra en la misma posición, pero esta conclusión sería errónea ya que los poderes públicos franceses conservan y utilizan todas las facultades de intervención al no haber ratificado el Convenio 154 OIT y no contar con una protección constitucional tan firme de la autonomía colectiva

\footnotetext{
18 Véase Van Rie et al. (2016), pág. 214, gráfico 3 y pág. 216, gráfico 5 .
}

(aunque en España esto solo sea el resultado de la interpretación ultrancista que se ha venido haciendo de estas normas), por contraposición al caso francés, en que existe un predominio absoluto de la norma legal (Rojot, en CCNCC 2004/95). En la última parte de este trabajo se propone una estrategia de reforma para corregir esta anomalía uniformista, incompatible con la gran heterogeneidad del tejido empresarial español.

\section{Una reforma integral de la legislación laboral en España}

Este último epígrafe estudia la revisión de la legislación laboral a partir de la Constitución española y sus normas de desarrollo, deteniéndose particularmente en la negociación colectiva, la contratación laboral y la resolución de conflictos. La reforma integral que aquí se propugna respeta absolutamente la protección que otorga el artículo 7 de la CE a la defensa de los intereses representados por sindicatos y asociaciones empresariales, ya que el propio artículo explicita claramente que tal defensa debe llevarse a cabo dentro del respeto a la CE y a la ley, de modo que la tarea regulatoria recae sobre esta última. El derecho a la negociación colectiva laboral que figura en el artículo 37.1 de la CE se remite también a la ley que lo garantice y que regule la fuerza vinculante de los convenios, lo que debe llevarse a cabo respetando la libertad de empresa y la defensa de la productividad, a las que se refiere el artículo siguiente, practicando políticas orientadas a favorecer el progreso social, la distribución regional y personal de la renta, la estabilidad económica y el pleno empleo, como señala el art. 40.

\subsection{La Ley de fomento y extensión de la negociación colectiva en España}

El segundo nivel regulatorio se encuentra en las leyes orgánicas que desarrollan los $\triangleright$ 
derechos fundamentales y especialmente la Ley Orgánica de Libertad Sindical, objeto a su vez del Convenio 87 de la OIT (C. 87, de 9 julio 1948), que es uno de los ocho convenios fundamentales de esta organización especializada de la $\mathrm{ONU}^{19}$. Las cláusulas del convenio strictu senso no plantean problemas para la reforma, aunque sí podrían plantearlo las recomendaciones de su Comité de libertad sindical, que han sido consideradas por el Tribunal Supremo como fuente de interpretación del mismo (Ojeda-Gutiérrez, 2015). En particular la reforma iría en contra de la recomendación según la cual la determinación del nivel de negociación se remita a la voluntad de las partes, aunque esta recomendación se hace a España en función del conjunto de convenios OIT y del resto de la normativa laboral vigente, ya que algo así no se ha aplicado a otros países firmantes del C. 87 en los que es la normativa legal la que tipifica y jerarquiza las prioridades y los contenidos atribuidos a cada nivel de negociación. Bastaría pues con adoptar en la reforma normativa una interpretación menos restrictiva del Convenio 154, perfectamente posible y a la que ya se ha hecho referencia.

En el tercer nivel se encuentra la normativa ordinaria y en primer lugar el Estatuto de los Trabajadores. La primera reforma debería afectar a la enumeración de fuentes de la relación laboral, diferenciando el carácter normativo de los convenios colectivos de eficacia general en un ámbito determinado de los acuerdos colectivos que tienen el carácter de contrato entre las partes representadas en la mesa de negociación.

La nueva redacción del artículo 3 debería limitarse a enumerar la jerarquía de fuentes, su tipificación y características vinculantes, dejando para una ley específica la definición

\footnotetext{
${ }^{19} \mathrm{El}$ otro convenio fundamental relacionado con los derechos de sindicación y de negoción colectiva es el $n^{\circ} 98$, cuyas prescripciones no contradicen en modo alguno las líneas de la reforma propuesta aquí. http://www.ilo.org/wcmsp5/groups/public/@ed_norm/@declara tion/documents/publication/wcms_095897.pdf
}

de las mismas y el establecimiento de jerarquías y prelaciones que ahora figuran de manera inconexa o redundante en los números 2, 3, 4 y 5 del mismo. El enunciado que se propone (suprimiendo estos otros números, subsumiéndolos en el primero) es el siguiente:

Artículo 3. Fuentes de la relación laboral.

Los derechos y obligaciones concernientes a la relación laboral se regulan:

a) Por las disposiciones legales y reglamentarias del Estado y de las comunidades autónomas en el ejercicio de sus competencias constitucionales.

b) Por los convenios colectivos que, reuniendo las condiciones exigidas por la ley, hayan alcanzado eficacia general en un ámbito determinado, directamente o a través de los procedimientos de extensión o ampliación regulados por aquella. Su contenido no afectará a las materias que la propia ley haya reservado para su regulación legal, a no ser que se trate de normas solo aplicables «en defecto de convenio o acuerdo colectivo». A su vez, en aquellas materias para las que la ley otorgue prioridad negociadora y preferencia de aplicación a los acuerdos colectivos o al contrato individual de trabajo los convenios colectivos de ámbito superior solo serán de aplicación en ausencia de los mismos. La administración laboral certificará la legalidad de los contenidos de los convenios colectivos, dando publicidad suficiente a los de ámbito superior a la empresa y facilitando el libre acceso al registro público de todos ellos, excepto si la difusión de sus contenidos afectase negativamente a la empresa directamente afectada ${ }^{20}$.

c) Por la voluntad de las partes manifestada en los acuerdos colectivos entre representantes de empresarios y trabajadores presentes efectivamente en la mesa de negociación con arreglo a los términos de representatividad y procedimientos previstos en la ley. En aquellas $D$

\footnotetext{
20 Como establece el Proyecto de Ley de Trabajo francés (Art. 9) y las leyes alemana, belga y holandesa.
} 
materias en que la ley no le otorgue preferencia de aplicación, el contenido de todo acuerdo colectivo respetará siempre la ley y lo establecido en el convenio colectivo de eficacia normativa general vigente en su ámbito, en caso de existir. La administración laboral certificará la legalidad de los contenidos de los acuerdos, dando publicidad suficiente a los de ámbito superior a la empresa y facilitando el libre acceso al registro público de todos ellos, excepto en los casos a los que se refiere la letra $b$ ) in fine.

La ley establecerá las condiciones en que acuerdos colectivos alcanzados en empresas individuales o en ámbitos concretos se denominarán y tendrán la consideración de convenio colectivo a los efectos previstos en la letra $b$ ) precedente.

d) Por la voluntad de las partes, manifestada en el contrato de trabajo, siendo su objeto lícito y sin que en ningún caso puedan establecerse en perjuicio del trabajador condiciones menos favorables o contrarias a las disposiciones legales, los convenios y los acuerdos colectivos, en sus respectivos ámbitos y de acuerdo con las prioridades de aplicación establecidas, excepto en aquellas materias en las que la normativa aplicable haya otorgado preferencia al contrato individual.

e) Por los usos y costumbres locales y las buenas prácticas profesionales, en todo aquello no previsto en las cuatro letras anteriores ${ }^{21}$.

La normativa de desarrollo a la que se refiere este artículo se encuentra actualmente en el título tercero del Estatuto de los Trabajadores (ET: artículos 82 a 92), que debería desgajarse del mismo para constituir una ley autónoma, denominada Ley de fomento y extensión de la negociación colectiva, y su reforma adoptarse independientemente de la del resto del Estatuto. A su vez, convendría hacer lo propio con el título segundo del ET (artículos 61 a 81)

\footnotetext{
${ }^{21}$ Aunque esta enumeración de fuentes amplíe la actual, la ley belga de 1968 (A. 51) enumera 13 niveles.
}

transformándolo en una ley específica sobre la representatividad de los agentes. Por su parte, el actual título primero ( $D e$ la relación individual de trabajo: artículos 1 a 60) debería reestructurarse por completo siguiendo la sistemática de reforma propuesta en Francia, aunque con dos, en lugar de tres títulos, estableciendo en el primero de ellos los derechos esenciales y en el segundo sus preceptos de desarrollo, diferenciando en cada caso lo que es derecho necesario de los preceptos de derecho dispositivo, solo aplicables en defecto de convenio, acuerdo colectivo o contrato individual, especificando qué nivel tiene preferencia aplicativa en cada materia. La suma de estas tres leyes constituiría el nuevo Estatuto de los Trabajadores.

Comenzando por la nueva Ley de fomento y extensión de la negociación colectiva, los grandes principios sobre los que debería articularse el texto pueden sintetizarse en un decálogo.

\section{1) Estructura general de la negociación colectiva}

Sin perjuicio de la existencia de acuerdos marco en cualquier nivel o ámbito de negociación - cuya aplicación efectiva requiere en todo caso la materialización en convenios y/o acuerdos colectivos de las obligaciones asumidas en ellos por las organizaciones firmantes-, la estructura de la negociación diferenciará a las empresas, según su tamaño, en grandes empresas (a partir de 250 trabajadores), empresas medianas (entre 50 y 249 trabajadores), pequeñas empresas (entre 11 y 49 trabajadores) y microempresas (hasta 10 trabajadores).

Con carácter excepcional la ley podrá prever que algunas materias de negociación especialmente relevantes puedan ser objeto de acuerdos interprofesionales, estableciendo el alcance, plazo de negociación y representatividad exigibles para su validez. Esta deslegalización tendría que producirse al mismo tiempo $\triangleright$ 
que la reforma propuesta, haciendo tabla rasa de la actualmente vigente so pena de vaciarla de contenido, dadas la limitaciones y contradicciones detectadas en la sucesión de normas que se han ido superponiendo en materia de ordenación de la estructura supraempresarial de la negociación colectiva. Además, la seguridad jurídica exige que la deslegalización de materias se produzca por ley expresa estableciendo plazos determinados para alcanzar acuerdos interprofesionales. En caso de no llegarse a ellos, el Gobierno recuperaría la facultad de regular esas materias por vía reglamentaria, pudiéndose dejar abierta la puerta para su sustitución por acuerdos interprofesionales posteriores, considerándose en este caso como normativa aplicable solo por defecto ${ }^{22}$.

\section{2) Negociación colectiva en las grandes empresas}

En las grandes empresas la negociación colectiva se lleva a cabo entre el empresario y el comité de establecimiento, empresa o grupo de empresas ${ }^{23}$. Estos últimos podrán negociar convenios únicos de grupo o estructurarlos en convenio de grupo/empresa/establecimiento (cuando en cada uno de estos niveles existan unidades con 50 o más trabajadores), fijando en los primeros las correspondientes prelaciones o preferencias de aplicación y las disposiciones aplicables por defecto. Si la ley ha reservado expresamente el tratamiento de materias específicas a acuerdos interprofesionales, y

\footnotetext{
22 Salvador del Rey Guanter (2014) observa el bucle que se produce entre los artículos 83 y 84 del ET, debido a la insuficiencia de preceptos puntuales sobre la jerarquía normativa. De ahí la conveniencia de la deslegalización de ámbitos y materias, ex novo y por un plazo temporal tasado, reservando las facultades de avocación en caso de no hacerse uso tempestivo de la misma. En caso de concurrencia entre acuerdos interprofesionales estatales y de comunidad autónoma, en aquellas materias que no rompan la unidad de mercado debería prevalecer siempre este último, aplicándose el estatal solo por defecto.

23 Del Rey Guanter (2014) señala también, con toda razón, que en la reforma de 2012, mientras la inaplicación es «temporal», la creación de una nueva unidad es estructural. Ambas técnicas de descentralización resultan confusas y prácticamente incompatibles.
}

estos se encuentran vigentes en el momento de la firma del convenio. este deberá respetar lo establecido en ellos. Los acuerdos interprofesionales suscritos durante la vigencia del convenio de empresa no serán de aplicación hasta que expire la vigencia de éste y se acuerde un nuevo convenio. En ausencia de los mismos el convenio colectivo de las grandes empresas solo está sometido a las disposiciones legales y reglamentarias vigentes en cada momento, incluidas las aprobadas en el transcurso de su vigencia ${ }^{24}$.

Para suscribir un convenio colectivo será preciso el acuerdo del comité de empresa por mayoría absoluta de sus miembros. Un número de miembros superior a la tercera parte del comité -o la sección de empresa de uno o más de los sindicatos más representativos en ese ámbito, en caso de existir- puede acordar con el empresario un proyecto de convenio, que para alcanzar validez deberá recibir el apoyo de la mayoría absoluta de los trabajadores a quienes va dirigido, mediante votación secreta convocada con las formalidades exigidas para la elección de representantes. Solo en ausencia de convenio colectivo de empresa el empresario o el comité de empresa -por acuerdo mayoritario en este caso- podrán solicitar a la autoridad laboral la extensión vertical y aplicación a la empresa del convenio colectivo de su rama de actividad y ámbito territorial vigente para las empresas medianas, en caso de existir. La autoridad acordará la extensión si aprecia que alguna de las partes, o las dos, no han negociado de buena fe, cuando constate la inexistencia de voluntad de subsanación en un plazo razonable, no superior a 18 meses. $\quad \square$

\footnotetext{
24 Rey Guanter (2014) demostró la imposibilidad de delimitar la enumeración de las materias en que el convenio de empresa debe tener prioridad aplicativa frente a los de ámbito superior, respecto a otras materias conexas que interactúan con las primeras y son susceptibles de desnaturalizar la pretensión de preferencias establecidas por el legislador, aduciendo como ejemplo la diferencia especiosa entre la "cuantía del salario base y los complementos salariales» y otras partidas remunerativas que tienen igual relevancia sobre el coste unitario del trabajo.
} 


\section{3) Empresas medianas con convenio colectivo}

Cuando una empresa mediana (de más de 49 y menos de 250 trabajadores) suscriba por sí misma un convenio colectivo bajo las condiciones previstas para los convenios de las grandes empresas se estará a lo dispuesto en el apartado 2) precedente, quedando solo sometido a los preceptos legales y reglamentarios y, eventualmente, a los de los acuerdos interprofesionales previstos por la ley, pero no a otros convenios o acuerdos supraempresariales ${ }^{25}$.

\section{4) Negociación colectiva en las pymes}

Con carácter general, la negociación colectiva supraempresarial para las empresas medianas y pequeñas se llevará a cabo por separado y los acuerdos colectivos alcanzados que reúnan las condiciones preceptivas para tener el carácter de convenio colectivo de eficacia general solo afectarán al ámbito profesional o de rama $y$ al grupo de empresas (medianas o pequeñas) para el que se haya negociado. Alternativamente, las pequeñas empresas podrán adoptar un convenio colectivo propio siempre y cuando el preconvenio negociado entre la empresa y los representantes del personal sea ratificado en votación secreta al menos por el 55 por 100 de la plantilla, quedando en tal caso la empresa eximida de aplicar los convenios o acuerdos supraempresariales. En todo caso estos últimos respetarán las condiciones y mecanismos de no aplicación previstos legalmente o acordados de acuerdo con la ley.

5) Convenios y acuerdos colectivos de ámbito negocial y tamaño de empresa

Para que los acuerdos colectivos a los que se refiere el apartado 4) precedente tengan la

25 Para Rey Guanter (2014) una vez formada la unidad empresarial de negociación su regulación puede diferenciarse «del nivel superior», ya que no hay concurrencia: solo una de las normas es aplicable. consideración de convenio colectivo de eficacia general en un ámbito determinado, las partes firmantes deben representar directamente, al menos, al 55 por 100 de los trabajadores y al 55 por 100 de las empresas del correspondiente ámbito de aplicación y de tamaño de empresas, para lo cual la autoridad laboral expedirá certificación de los resultados de las últimas elecciones a representantes celebradas en el mismo y de las empresas afiliadas a las organizaciones empresariales presentes en la mesa de negociación, midiendo el porcentaje de representación en relación al censo de empresas en alta en la Seguridad Social del correspondiente ámbito negocial y de tamaño. La delimitación de los ámbitos de negociación lo deciden libremente las partes negociadoras, por acuerdo mayoritario de trabajadores y número de empresas, respetando siempre la estructura negocial por tamaños. En ausencia de acuerdo sobre ámbitos mediará la autoridad laboral, decidiendo, en su caso, a la vista de dictámenes solventes acerca de la homogeneidad productiva y territorial del correspondiente ámbito de negociación.

\section{6) Acuerdos colectivos: procedimiento de extensión horizontal}

De no existir convenio colectivo de eficacia general aplicable, los acuerdos colectivos alcanzados en cada ámbito empresarial de tamaño similar serán de aplicación exclusivamente a las empresas representadas directamente en la mesa de negociación. Cuando las empresas y el número de trabajadores afectados por un acuerdo equivalgan a la tercera parte del número de empresas y trabajadores del correspondiente ámbito y tamaño, las comisiones paritarias establecidas por los mismos podrán solicitar ante la autoridad laboral, por mayoría de las dos partes firmantes, la extensión del acuerdo a todo el ámbito negocial de las empresas de tamaño similar. La extensión se producirá $\triangleright$ 
cuando la autoridad laboral constate la adhesión voluntaria hasta alcanzar el 55 por 100 del número de empresas y trabajadores del correspondiente ámbito y/o la solicitud de los comités de empresa del 55 por 100 de las empresas del mismo.

En caso de no alcanzarse las condiciones requeridas para su extensión y conversión en convenio, las empresas adheridas voluntariamente quedarán incluidas en el acuerdo mientras que las restantes quedarán obligadas a negociar un convenio propio en un plazo de dieciocho meses, transcurrido el cual la comisión paritaria podrá volver a instar la extensión. La autoridad laboral convertirá el acuerdo de ámbito en convenio colectivo de eficacia general en el mismo cuando la suma de las empresas acogidas al acuerdo correspondiente, sumadas a las que hayan alcanzado convenio propio supere el 55 por 100 del número de empresas y de trabajadores, no aplicándose el convenio a las empresas que concluyeron uno propio antes de la extensión.

\section{7) Acuerdos colectivos: procedimiento de separación horizontal}

Cuando en un determinado ámbito negocial de pymes existieren dos o más acuerdos, con empresas de similares características en cada uno de ellos aunque diferentes a las del otro, la comisión paritaria de uno de ellos, por acuerdo mayoritario, podrá proceder a la separación de los dos ámbitos negociales, comunicándolo a la autoridad laboral, que certificará la legalidad del mismo. En caso de conflicto sobre ámbitos entre las correspondientes comisiones paritarias mediará la autoridad laboral, decidiendo, en su caso, a la vista de dictámenes solventes acerca de la homogeneidad productiva y territorial de los nuevos ámbitos de negociación. Cada uno de los acuerdos colectivos de estos últimos quedará sometido eventualmente a las mismas condiciones de extensión horizontal enumeradas en el apartado 6) precedente.

\section{8) Acuerdos colectivos: procedimiento de extensión vertical}

Cuando en un determinado ámbito negocial y grupo de empresas de similar tamaño (medianas o pequeñas) no exista convenio colectivo ni acuerdos colectivos que reúnan las condiciones para solicitar la extensión o separación horizontal de los apartados 6) y 7), existiendo convenio colectivo para ese ámbito en el otro grupo de empresas por tamaño (pequeñas o medianas), la comisión paritaria de este último podrá solicitar la extensión vertical del convenio a las empresas de ese ámbito que no cuenten con convenio de empresa propio y no se encuentren incluidas en un acuerdo colectivo.

La autoridad laboral concederá la extensión cuando lo solicite el 55 por 100 de los comités de empresa y el 55 por 100 de las empresas que vaya a verse afectadas, pudiendo estas empresas en el trascurso del procedimiento adherirse a alguno de los acuerdos preexistentes en su propio grupo de tamaño, en cuyo caso no se verán afectadas por la extensión. Cuando en el transcurso del proceso de extensión vertical, como consecuencia del número de adhesiones recibidas (incluidas las empresas con convenio propio, a los solos efectos de este cómputo) alguno de los acuerdos preexistentes en su ámbito y grupo de tamaño alcance las condiciones exigidas para la extensión horizontal, cesará el procedimiento de extensión vertical, iniciándose de oficio otro de extensión horizontal (que no afectará a las empresas con convenio).

\section{9) Acuerdos colectivos: procedimiento de ampliación}

Con carácter excepcional podrá solicitarse la ampliación de un número limitado de cláusulas $\triangleright$ 
de un convenio a empresas no comprendidas en su ámbito negocial cuando la inexistencia de representantes con capacidad de negociación impida la negociación colectiva en el mismo y se hayan producido como consecuencia de ello distorsiones de la competencia, detectadas por la autoridad responsable de la misma, o prácticas laborales abusivas denunciadas reiteradamente y verificadas por la inspección de trabajo. Esta ampliación podrá instarla la autoridad de la competencia, la inspección de trabajo o la comisión paritaria del convenio cuyas cláusulas se pretenden extender. La ampliación solo afectará a aquellas cláusulas imprescindibles para corregir las distorsiones y prácticas abusivas previamente denunciadas.

\section{0) El dialógo social en las microempresas}

Las empresas de menos de once trabajadores podrán negociar un convenio colectivo propio cuando dispongan de representante de personal y el preacuerdo negociado con el empleador sea ratificado al menos por el 55 por 100 de la plantilla. Alternativamente, el empleador puede adherirse, voluntariamente o por acuerdo mayoritario con sus trabajadores, al convenio o a alguno de los acuerdos colectivos vigentes para las pequeñas empresas en su ámbito negocial territorial. Solo podrá instarse extensión vertical del convenio o de alguno de estos acuerdos colectivos a las microempresas de un determinado ámbito negocial y territorial cuando más del 55 por 100 de ellas, comprendiendo al menos al 55 por 100 de los trabajadores, se hayan adherido previamente al mismo. Cuando la adhesión alcance solo a la tercera parte de empresas y trabajadores de un determinado ámbito de microempresas la comisión mixta del acuerdo o convenio correspondiente podrá instar la extensión vertical. En caso de no reunirse las adhesiones voluntarias necesarias para ello, la propia comisión mixta podrá elaborar recomendaciones genéricas sobre criterios orientadores para la determinación de salarios y otras condiciones de empleo en las microempresas de su ámbito correspondiente, sin vaciar de contenido en ningún caso la facultad autónoma de su materialización concreta en cada empresa, que solo vendrá obligada a respetar las disposiciones legales y reglamentarias aplicables en cada caso.

Sin perjuicio de que la reforma integral de la legislación laboral aconseje revisar en su momento completamente el título segundo del ET, actualizando y corrigiendo las incidencias que han venido observándose desde el momento mismo de su entrada en vigor, la puesta en marcha de una reforma estructural de la negociación colectiva como la aquí propuesta obligará a abordar específicamente las insuficiencias de la regulación sobre la representación de las empresas, que actualmente se encuentra en un limbo prácticamente inextricable (Menéndez, 2014, p. 28).

El hecho de que el Tribunal Constitucional haya interpretado que las asociaciones empresariales no se incluyen dentro del derecho a la libertad sindical y sí del derecho más amplio de asociación protegido por el artículo $22 \mathrm{CE}^{26}$, obligadas tan solo a inscribirse en un registro a efectos de publicidad (art. 22.3 CE), ello no obsta para que la norma que regule la nueva negociación colectiva establezca la obligatoriedad de que para participar en la negociación supraempresarial las asociaciones representativas de empresarios se encuentren inscritas en un registro especial de la autoridad laboral en que consten los afiliados a cada una de ellas y sus características, a efectos exclusivamente $\triangleright$

${ }^{26}$ Según su exposición de motivos, la Ley Orgánica de Libertad Sindical «no se ocupa... de desarrollar el derecho a la libre sindicación de los empresarios por entender que basta a ese respecto, en relación con el desarrollo legislativo del artículo 28,1 de la Constitución española, constitucionalizar y mantener la plena vigencia de lo establecido en materia de asociacionismo empresarial por la Ley 19/1977, de 1 de abril, sobre regulación del derecho de asociación sindical"» (de los trabajadores y empresarios), como hizo la disposición derogatoria de la propia LOLS. Tal cosa resulta radicalmente insuficiente y es necesario desarrollarla para disponer de un registro que delimite ámbitos negociales y de representación. 
de certificar la representatividad de las mismas en sus correspondientes ámbitos negociales, de modo que sería necesario que la ley que desgaje en su día el título segundo del ET amplíe su denominación y ámbito regulatorio al de los derechos de representación colectiva, de elección de representantes, de reunión de los trabajadores en la empresa, y del registro de miembros de las asociaciones empresariales.

\subsection{Algunas implicaciones de la nueva negociación colectiva: la necesidad de romper la segmentación contractual}

Una de las piezas de la normativa laboral más entrelazada con las ineficiencias de la negociación colectiva es la segmentación del mercado de trabajo derivada de la normativa sobre terminación de contratos, que establece una divisoria prácticamente infranqueable entre contratados temporales (sometidos a precariedad y escasamente beneficiarios de la negociación colectiva) y contratados permanentes (beneficiarios máximos de la negociación colectiva, protegidos de las fluctuaciones cíclicas del empleo por el colchón amortiguador de los temporales, por lo que apenas sufren las consecuencias de una negociación irresponsable o simplemente no coordinada con la evolución macroeconómica). Romper esta segmentación es el complemento imprescindible de la reforma de la negociación colectiva (Espina, 2016c).

La vía elegida inicialmente por Francia, sería también recomendable en España, ya que, al no contemplarse en nuestro caso que la indemnización por despido sea una «indemnización por daños", sería bueno recuperar la diferenciación por tamaño de empresas que pretendió hacer la Ley Macron, manteniendo los niveles máximos existentes pero aplicándoselos exclusivamente a las grandes empresas, modulando sus cuantías para las medianas $\mathrm{y}$, sobre todo, para las más pequeñas y para las microempresas $^{27}$, como sucede en Alemania y Francia, manteniendo en todo caso la nulidad y la proscripción de discriminación y acoso.

Aplicando esta lógica, las escalas recomendables para las indemnizaciones por despido en España según tamaño de empresa serían las que aparecen en el Gráfico 1, según el cual las indemnizaciones por despido improcedente en las grandes empresas sería de 20 días el primer año, 25 el segundo y 33 días a partir del tercero, con un límite igual al actualmente existente (24 meses, para 22 años de antigüedad). Para las pequeñas empresas el primer año tendría una indemnización de doce días (lo que implica que la empresa no encontraría incentivo para usar el contrato temporal y que durante el primer año la indemnización sería igual a la del despido procedente); el segundo año aumentaría a 16 días y a partir del tercero a veinte días por año, con un límite de doce mensualidades, que se alcanzaría a los 19 años de antigüedad. Para las medianas empresas la escala de indemnizaciones por despido improcedente equivaldría exactamente al promedio entre las de las pequeñas y las grandes empresas: 16 días el primer año, con límite de dieciocho meses a los 20 años. $Y$ para las microempresas sería siempre de doce días con límite de ocho meses a los veinte años.

En cambio, para el despido procedente por causas económicas, organizativas, productivas y técnicas se establecerían solo tres escalas: $D$

\footnotetext{
27 Encontrándose ya actualmente estas últimas excluidas de los procedimientos de despido colectivo, que solo se aplican cuando incluye a más de diez trabajadores, o a más de cinco cuando afecta a toda la plantilla (artículo 51.1). Según el artículo 52.c, en caso de no ser así se considera despido objetivo. Una alternativa consistiría en excluir a las microempresas de la protección del despido improcedente, como sucede en Alemania y Francia, aunque manteniendo la nulidad y la proscripción de discriminación y acoso, en cuyo caso se les aplicarían las indemnizaciones por despido improcedente de las pequeñas empresas, pero esto solo en caso de que tal exclusión fuera compatible con el Convenio 158 de la OIT.
} 


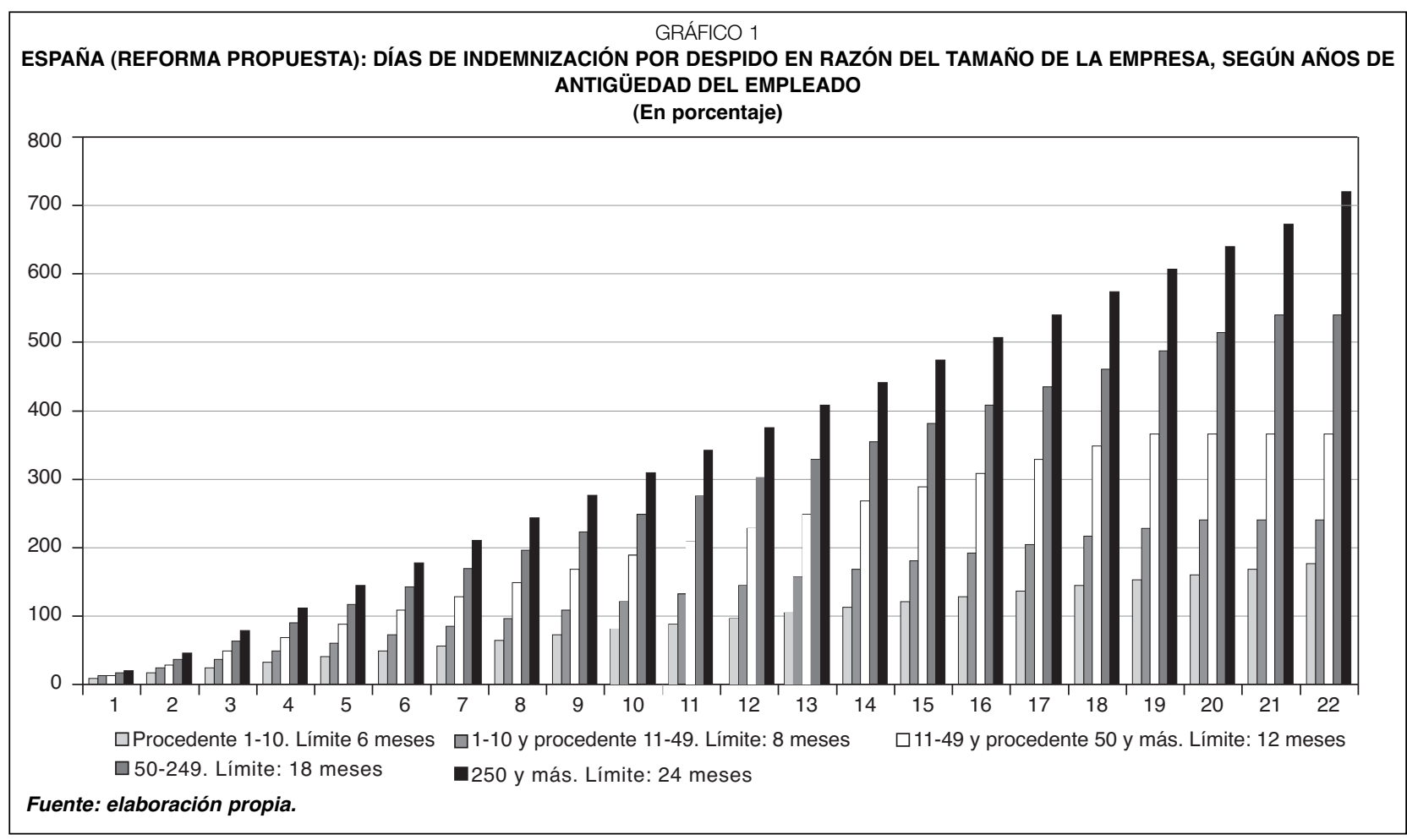

la de las microempresas hasta 10 trabajadores, la de las empresas hasta 49 trabajadores y la de las que tienen más de 50. La indemnización por despido procedente para las microempresas sería de ocho días por año con límite de seis meses; las de las empresas con más de 10 y menos de 50 trabajadores se igualaría con la del contrato temporal (aplicable también a toda forma de contrato que no sea el contrato por tiempo indefinido), mientras que la de las empresas medianas y grandes equivaldría a la escala del despido improcedente para las pequeñas empresas. De esta forma se avanzaría en la equiparación de estas indemnizaciones con las vigentes en el conjunto de la OCDE, ya que según la base de datos sobre protección del empleo en esta organización las actualmente vigentes duplican a las francesas $^{28}$ y son muy superiores a las vigentes en promedio en el conjunto de países miembros,

\footnotetext{
${ }^{28}$ En una escala de 0 a 6, en diciembre de 2013 las indemnizaciones españolas se situarían en 4 , las francesas en 2 y las medias de la organización en 1,5. Véase: http://www.oecd.org/els/emp/EPLdata.xIsx
}

como se observa en los conceptos 7 a 9 del gráfico $\mathrm{n}^{\circ} 5$ de OECD $(2014)^{29}$.

La eliminación de la autorización administrativa, previa a los despidos colectivos o a la modificación sustancial de las condiciones de trabajo llevada a cabo en la última reforma y su sustitución por la revisión de estos procedimientos ante la jurisdicción social a través de la acción por despido colectivo, ha producido un aumento de la inseguridad jurídica que podría limitarse ofreciendo a las empresas una alternativa voluntaria de supervisión por la autoridad laboral de que se han respetado las normas de procedimiento (que son el motivo más frecuente de anulación jurisdiccional). Esta alternativa consistiría en que, una vez finalizado el preceptivo período de consultas sin acuerdo, la empresa informe de todo lo actuado a la autoridad laboral para que esta se pronuncie con $\triangleright$

29 En Italia, la Jobs Act (Decreto legislativo 23/2015), establece también indemnizaciones por despido objetivo injustificado con máximos entre seis y veinticuatro meses según la empresa tenga menos o más de 15 asalariados, añadiendo un procedimiento exprés con indemnización máxima de 18 meses. La ley introduce un contrato intermedio con indemnización creciente. Véase $\mathrm{C}$. Antonin (9-3-2016). 
carácter previo a realizar la comunicación de la decisión empresarial a los trabajadores (aplicándose la presunción de silencio positivo transcurrido un plazo razonable: de siete días para las pequeñas empresas, quince para la medianas y veinte para las grandes).

En caso de apreciar infracciones o inobservancias a las reglas del procedimiento la autoridad laboral debería comunicarlo a la empresa y a los representantes de los trabajadores, recomendando la forma de subsanación. En lugar de la redacción actual del artículo 51.2 (según el cual «las advertencias y recomendaciones remitidas a las partes no supondrán, en ningún caso, la paralización ni la suspensión del procedimiento») la autoridad laboral estaría facultada en tales casos para prorrogar el período de consultas, dentro de los plazos previstos por la Directiva europea sobre despidos colectivos. En general, los plazos del procedimiento ordinario vigente son los establecidos por ese mismo artículo, de acuerdo con la Directiva (duración no superior a treinta días naturales, o de quince en el caso de empresas de menos de cincuenta trabajadores). En caso de optar la empresa, si existiera desacuerdo, por la supervisión voluntaria, la autoridad laboral podría prorrogar tales plazos, de modo que la comunicación del despido no se produjera antes de transcurrir sesenta días desde que la empresa mediana realizó la comunicación inicial del expediente (cuarenta y cinco días, en las empresas con menos de 50 trabajadores; setenta y cinco en las de más de 250). El sometimiento voluntario por parte de la empresa a la supervisión del procedimiento por la autoridad laboral debería llevar aparejada la inaplicación del artículo 51.6 del ET, en lo que se refiere a la facultad de la representación laboral para entablar conflicto colectivo a través de la vía regulada en el artículo 124 de la Ley 36/2011 (de 10 de octubre), de la jurisdicción social, algo previsto en el Convenio 158 de la OIT (art. 8.2), que admite la inexistencia de recurso cuando existe autorización administrativa previa (limitada en este caso solo al procedimiento).

Cabría avanzar todavía más en la eliminación de los grandes desequilibrios entre las dos formas de contratación reduciendo a un trimestre el plazo de pérdidas anualizadas para considerar objetivo el despido en las microempresas (como en Francia) y reforzando la indemnización del contrato temporal, aplicándole la escala correspondiente de indemnizaciones por despido procedente por causas económicas, organizativas, productivas y técnicas, pero no solo a la duración del contrato actual, sino a la acumulación de contratos realizados por la empresa con el mismo trabajador a lo largo de su vida activa (respetando en todo caso las interrupciones legales).

Hay que decir también que España se distancia mucho de los estándares vigentes en contenido y número de restricciones a la contratación temporal, como se observa en los pares de columnas 14 a 17 del gráfico 5 de OECD (2014), en el que ocupa el séptimo lugar dentro del área, como refleja el gráfico que figura en OECD (2013/88). En contraste con Francia, esto produce una constante rotación de trabajadores que merma la acumulación de experiencia y daña sus posibilidades de conversión en permanentes. En Espina (2016a) se señaló que, en lugar de seguir restringiendo con excesivo rigor su duración absoluta, sería preferible llevar a cabo una limitación del volumen total de contratos temporales (como hizo en Italia la Jobs Act).

La forma de aplicar esta estrategia de limitación de la temporalidad en España -sin perjudicar las perspectivas de conversión de estos contratados en empleo permanente- podría consistir en que los límites máximos de duración del contrato de duración determinada, que figuran en el artículo 15 del ET, se transformaran en derecho dispositivo: «aplicable exclusivamente en ausencia de convenio o acuerdo $D$ 
colectivo,» aunque este carácter dispositivo debería ser relativo, no absoluto, y operar solo «cuando la empresa no supere el límite máximo legalmente establecido para el porcentaje total de horas temporales contratadas, o así se acuerde en los planes negociados de reducción de la contratación temporal para alcanzarlo o para avanzar más en esa dirección».

Una vez adoptado el método de control de la temporalidad mediante el límite al porcentaje de horas contratadas podrían suavizarse también las restricciones legales existentes para la recontratación de trabajadores que ya han tenido contrato temporal con la misma empresa, como método más eficiente para incentivar su conversión en fijo. Finalmente la reestructuración de la contratación y el rápido avance hacia la eliminación de la segmentación permitiría hacer una poda radical de la maraña de incentivos a la contratación (que merman la cotización a la Seguridad Social de manera temeraria y se prestan al fraude), dejando subsistir solo aquellos incentivos dirigidos hacia colectivos que experimentan discriminación grave y permanente en el mercado de trabajo.

Ya quedó dicho que, encontrándose todos los bloques constitutivos de la regulación del mercado de trabajo profundamente trabados entre sí, la reforma de una de sus piezas esenciales -como lo son sin duda alguna la negociación colectiva y la normativa sobre segmentación de contratos y extinción de la relación laboral- solo resultaría óptima insertándola en una reforma regulatoria integral.

Durante el período de elaboración y adopción de la nueva legislación sobre negociación colectiva una comisión de expertos de alto nivel debería trabajar para elaborar un proyecto de normas básicas de la relación de trabajo. Una vez fijado el proyecto de normativa básica debería entrarse en el examen pormenorizado de los sesenta artículos del título primero del ET para clasificar sus normas en seis epígrafes: a) normas obsoletas, directamente derogables o deslegalizables; b) normas redundantes y/o prolijas, que deben someterse a una profunda simplificación, con su eventual desarrollo en vía reglamentaria, de modificación más flexible; c) normas de derecho necesario que deberían mantenerse en su redacción actual; d) normas de derecho necesario que deberían añadirse, en consonancia con la nueva normativa básica y con las reformas de la negociación colectiva y de la contratación, de las que ya se ha hablado; e) normas que deberían ser objeto de acuerdos interprofesionales, señalando el nivel territorial aconsejable para hacerlo y el plazo de tiempo prudencial para llevarlo a cabo, en ausencia de lo cual debería producirse la actuación normativa, legal o reglamentaria, en el nivel correspondiente (estatal o autonómico); f) normas que deben convertirse en derecho dispositivo y mantenerse para su aplicación solo «en ausencia de pacto», realizando propuestas sobre el significado de su carácter dispositivo (absoluto o relativo) y el nivel recomendable para llevar a cabo los pactos modificativos: convenio, acuerdo colectivo o contrato individual ${ }^{30}$.

\section{Conclusión}

El estado esclerótico de nuestra negociación colectiva-cuyas consecuencias negativas para el empleo en la pymes y en los territorios con menor renta per cápita se estudiaron en Espina (2016c) y resultan acordes con Flanagan (1999) - se debe a un marco institucional y una normativa aplicable en España completamente anómala dentro del grupo de países más significativos de la UE, como se estudia en la segunda parte, tras analizar en la primera los efectos y limitaciones de las últimas reformas. $D$

30 Un examen pormenorizado de estas distinciones, aplicadas a la redacción del Estatuto de los Trabajadores vigente en 2001 puede verse en Sala Franco (Dir.) (2001). 
Esta anomalía se ha imputado a la ratificación por España del Convenio 154 de la OIT, que propugna la autonomía de los agentes colectivos y un nivel mínimo de actuación regulatoria por parte de los Estados, aunque caben interpretaciones de este convenio y de su eficacia normativa mucho más laxas que las que se han venido haciendo en nuestro país, siempre y cuando se complete la Constitución con una regulación adecuada, de acuerdo con lo previsto en su articulado.

La tercera parte del trabajo se pronuncia en favor de acometer simultáneamente la adopción de dos nuevas leyes: la Ley de fomento y extensión de la negociación colectiva, y la Ley de representación colectiva, de elección de representantes, de reunión de los trabajadores en la empresa, y del registro de miembros de las asociaciones empresariales, en sustitución de los títulos III y II (respectivamente) del Estatuto de los Trabajadores devolviendo el derecho constitucional a la negociación colectiva a los representantes de los trabajadores y de las empresas en la medida de lo razonablemente factible y, en todo caso, en la gran empresa.

No se dañaría con ello el ejercicio de este derecho a escala supraempresarial allí donde este es el nivel más eficiente, pero se trataría de dotarlo de una estructura que tome en consideración la heterogeneidad del tejido empresarial, de delimitar con precisión la representatividad y la capacidad de negociación de los agentes en cada ámbito y de establecer procedimientos efectivos de extensión y ampliación homologables con los de los países de nuestro entorno, abandonando el supuesto de eficacia general innata de todo convenio colectivo por el mero hecho de denominarse así, independientemente de la representatividad de los negociadores, algo que resulta nocivo a largo plazo incluso para quienes se consideran beneficiarios de esa regulación (Thelen-Wijnbergen, 2003).

En paralelo con ello convendría adoptar una nueva ley de terminación del contrato de trabajo que contribuya a corregir sustancialmente la segmentación del empleo entre contratados temporales e indefinidos, ya que tal divisoria interactúa con las ineficiencias de la negociación colectiva formando un bucle o círculo vicioso que se retroalimentan, hasta el punto de situar a España en uno de los puestos de cabeza de la OCDE en materia de segmentación contractual ( $\mathrm{y}$ de rigidez regulatoria en ambos tipos de contrato) y en tasa de desempleo (especialmente juvenil: Boeri-Jimeno, 2015).

Finalmente se propugna insertar todo ello en un proceso de rediseño integral del Estatuto de los Trabajadores que podría coordinarse con la que está emprendiendo el Gobierno francés -que, tras la accidentada etapa de tramitación de la Ley El Khomri, se mantiene en pie-, para lograr la simplificación, la delimitación clara de las normas de derecho necesario erga omnes del título I y del derecho dispositivo, a través de la negociación colectiva, así como la normativa aplicable en defecto de esta última. Tales iniciativas podrían servir de estímulo a la adopción de una normativa del mismo carácter a escala de la UEM, como la que se propuso en Espina (2016a y 2016b).

\section{Bibliografía}

[1] ANTONIN, C. (2014). «Réforme du marché du travail en Italie : Matteo Renzi au pied du mur». Note de l'OFCE $n^{\circ} 48 / 1$, diciembre. Disponible en:

http://www.ofce.sciences-po.fr/pdf/notes/ 2014/note48.pdf

[2] BANDE, R.; FERNÁNDEZ, M. y MONTUENGA; V. M. (2010). «Desequilibrios territoriales en el mercado laboral y estructura de la negociación colectiva». Papeles de Economía Española, $\mathrm{n}^{\circ} 124$, julio, pp. 193-213.

[3] BARTH, E.; BRYSON, A.; DAVIS, J. y FREEMAN, R.B. (2016). «Wage inequality: The spatial dimension». VOX (en línea) $18 \mathrm{de}$ julio de 2016. Disponible en:

http://voxeu.org/article/wage-inequality-spa tial-dimension 
[4] BENTOLILA, S. y JIMENO, J. F. (2002). «La Reforma de la Negociación Colectiva en España", en J. Aurioles et al. (eds.), Cuestiones Clave de la Economía Española, Sevilla: centrA. Disponible en:

ftp://ftp.cemfi.es/pdf/papers/sb/benjimeno.pdf

[5] BENTOLILA, S.; IZQUIERDO, M. y JIMENO, J.F. (2010). «Negociación colectiva: La gran reforma pendiente». Papeles de Economía Española, $\mathrm{n}^{\circ} 124$, julio, pp. 176-192.

[6] BENTOLILA, S.; DOLADO, J. J. y JIMENO, J. F. (2012). "The New New Labor Market Reform in Spain: Objectives, Instruments and Shortcomings". CES-Ifo-DICE, Journal for International Comparisons (2012), $\mathrm{n}^{\circ} 10, \mathrm{pp}$. 3-8.

[7] BOERI, T y JIMENO, J. F. (2015). The Unbearable Divergence of Unemployment in Europe, BdE . Documento de trabajo $\mathrm{n}^{\circ} 1534$.

[8] CCNCC (2004). La negociación colectiva en Europa. Comisión Consultiva Nacional de Convenios Colectivos, MTAS.

[9] CCNCC (2015). Estructura de la negociación colectiva. XXVII jornadas de estudio sobre negociación colectiva. Comisión Consultiva Nacional de CC. CC., MEYSS.

[10] CONDE-RUIZ, J. I.; FELGUEROSO, F. y GARCIA PEREZ, J. I. (2010). «Las reformas laborales en España. Un modelo agotado». Papeles de Economía Española, $n^{\circ} 124$, julio, pp. 128-147.

[11] CRUZ VILLALÓN, J. (2015a). «La nueva regulación de la negociación colectiva: ruptura del equilibrio en las relaciones laborales en aras de una flexibilidad sin consenso». Temas para el Debate, $n^{\circ}$ 249-250 (agosto-septiembre), pp. 28-30.

[12] VILLALÓN, J. (Dir.) (2015b). La incidencia de la reforma laboral de 2012 sobre la estructura de la negociación colectiva, MEYSS, Colección Informes y Estudios Serie Relaciones Laborales $\mathrm{n}^{\circ} 107$.

[13] DOLADO, J. J. (2012). «The Pros and Cons of the Latest Labour Market Reform in Spain», Spanish Labour Law and Employment Relations Journal. vol. 1, $\mathrm{n}^{\circ}$ 1-2. Madrid: Univ. Carlos III. Disponible en:

http://e-revistas.uc3m.es/index.php/SLLERJ/ article/view/1549

[14] DOLADO, J.J.; FELGUEROSO, F. y JIMENO, J.F. (1997). "The effects of minimum bargained wages on earnings: Evidence from Spain». European Economic Review, vol. 41, Issues 3-5, april, pp. 713-721.
[15] DOLADO, J.J.; FELGUEROSO, F. y JANSEN, M. (2010). «El conflicto entre la demanda de flexibilidad laboral y la resistencia a la reforma del mercado de trabajo». Papeles de Economía Española, n 124, julio, pp. 84-96.

[16] ESPINA, A. (2016a). «La reforma de la ley de trabajo en Francia: un caso de estudio". Boletín Económico de ICE, $\mathrm{n}^{\circ} 3076$, junio.

[17] ESPINA, A. (2016b). «La negociación colectiva en Alemania: desarrollo histórico, diseminación continental y reformas». Boletín Económico de ICE, $\mathrm{n}^{\circ}$ 3078, agosto.

[18] ESPINA, A. (2016c). «Anomalías de la negociación colectiva en España: esclerosis, segmentación, desequilibrios y colusión».Boletín Económico de ICE, $\mathrm{n}^{\circ} 3079$, septiembre.

[19] EUROFOUND (2015). Developments in working life in Europe: EurWORK an. Rev. 2014.

[20] IMF (2016). IMF Country Report No. 16/219. Euro Area Policies. 2016 Article IV Consultation. Disponible en :

http://www.imf.org/external/pubs/ft/scr/2016/ cr16219.pdf

[21] FALGUERA, M. À. (2012). «La normativa de la OIT y su translación en el ordenamiento interno por la sala de lo social del tribunal supremo. Algunas reflexiones de futuro tras la última reforma laboral». Jurisdicción Social, $n^{\circ} 123$, agosto.

[22] FERNÁNDEZ DE GUEVARA, J. (2012). «Las diferencias de productividad entre las empresas españolas en la expansión y la crisis». Cuadernos Económicos de ICE $\mathrm{n}^{\circ} 84$.

[23] FERNÁNDEZ, M., MONTUENGA, V.M. y BANDE, R. (2010). "Las tasas de paro regionales españolas: convergencia o polarización». IDEGA, Área de Análise Económica, DT 40.

[24] FLANAGAN, R. J. (1999). «Macroeconomic Performance and Collective Bargaining: An International Perspective». Journal of Economic Literature, vol. 37, $\mathrm{n}^{\circ} 3 \mathrm{pp}$. 1150-1175.

[25] GOERLICH PESET, J. M. (2008). «La reforma de la negociación colectiva: procedimiento negociador y eficacia de los convenios", en: Sala Franco, t. (Ed), La reforma del sistema de Negociación Colectiva y el análisis de las cláusulas de revisión salarial, MTIN, pp. 57-98.

[26] GOERLICH PESET, J. M. (2014). «La negociación colectiva en la Constitución; una mirada crítica». Revista del Ministerio de Empleo y Seguridad Social, $n^{\circ} 108$, p. 253-74. 
[27] JIMENO, J.F. y BENTOLILA, S. (1998). «Regional unemployment persistence (Spain, 1976-1994)». Labour Economics, vol. 5, Is. 1, marzo, pp. 25-51.

[28] HAUCAP, J. y WEY, C. (2004). «Unionisation structures and innovation incentives». The Economic Journal 114 (494), C149-C165.

[29] MALO, M. Á. (2012). «La reforma laboral de 2012: Cambios e incertidumbres». Papeles de Economía Española, $\mathrm{n}^{\circ} 133$, noviembre, pp. 84-92.

[30] MENÉNDEZ SEBASTIÁN, P. (2014). «El derecho de libertad sindical». Revista del Ministerio de Empleo y Seguridad Social, $\mathrm{n}^{\circ} 108$, pp. 227-251.

[31] MINANDO, A.; REQUENA, F. y SERRANO, G. (2013). «Movimientos migratorios en España antes y después de 2008». Papeles de Economía Española, $\mathrm{n}^{\circ} 138$, diciembre, $\mathrm{pp}$. 80-97.

[32] OECD (2014). The 2012 Labour Market Reform in Spain: A Preliminary Assessment.

[33] OECD (2016). Emplomen Outlook 2016.

[34] DEL REY GUANTER, S. (2014). «Estructura de la negociación colectiva y prioridad del nivel de empresa tras la reforma laboral de
2012». Revista del Ministerio de Empleo y Seguridad Social, $\mathrm{n}^{\circ}$ extraordinario, pp. 201213.

[35] SALA FRANCO, T. (Dir.) et alía (2001). «Los límites legales al contenido de la Negociación Colectiva. El alcance imperativo o dispositivo de las normas del Estatuto de los Trabajadores». MTAS, Colección Informes y Estudios (Serie Relaciones Laborales, $n^{\circ} 39$ ).

[36] SIMÓN, H. (2010). «La negociación colectiva y la estructura salarial en España». Papeles de Economía Española, nº 124, julio, pp. 214228.

[37] STEPHEN J. y WOLFGANG SCHROEDER, S. (2007). «Why Are German Employers +Associations Declining? Arguments and Evidence» Comparative Political Studies, vol. 40, $n^{\circ} 12$, December, pp. 1433-1459.

[38] THELEN, K. y VAN WIJNBERGEN, C. (2003). «The Paradox of Globalization. Labor Relations in Germany and Beyond". Comparative Political Studies, vol. $36, \mathrm{n}^{\circ} 8$, october, pp. 859-880.

[39] VAN RIE, T.; MAES, R. y DION, D. P. (2016). «Social Dialogue». Employment and Social Developments in Europe 2015. 